\title{
COMPARAÇÃO DE METODOLOGIAS PARA PREENCHIMENTO DE FALHAS EM BANCO DE DADOS PLUVIOMÉTRICOS: MÉDIA ARITMÉTICA X PONDERAÇÃO REGIONAL COM BASE EM REGRESSÃO LINEAR.
}

\author{
Nathália Karoline de Carvalho Soares ${ }^{(a)}$ e Charlei Aparecido da Silva ${ }^{(b)}$ \\ . ${ }^{(a)}$ Mestra em geografia e aluna de doutorado do programa de pós-graduação em geografia da Universidade Federal \\ da Grande Dourados. Contato: nathy.c.soares@gmail.com \\ ${ }^{(b)}$ Professor pós-doutor, titular do programa de pós graduação em geografia da Universidade Federal da Grande \\ Dourados. Contato: charleisilva@ufgd.br
}

Eixo: Climatologia em diferentes níveis e escalares: mudanças e variabilidades.

\section{Resumo}

O presente trabalho visa demonstrar a comparação nas metodologias para o preenchimento de falhas em banco de dados pluviométricos. A metodologia é derivada do projeto de tese "A expansão da cana-deaçúcar no Mato Grosso do Sul: Correlações entre o quadro de mudanças climáticas globais, a matriz energética de biocombustíveis e o regime das chuvas da região centro-sul no período de 1980 a 2015 ". A comparação entre os métodos citados no título do artigo surgiu da necessidade do preenchimento das falhas presentes nos postos pluviométricos que servirão como base para algumas respostas que buscamos para saber se está havendo (ou não) mudanças nos padrões de chuva das regiões mais cobertas pelas usinas sucroalcooleiras do Estado do Mato Grosso do Sul. Assim, buscou-se, após estudo das duas metodologias, aplicar na versão final da tese aquela que mais se enquadrou com os dados disponíveis.

Palavras chave: Mudanças climáticas, chuva e Mato Grosso do Sul.

\section{Introdução}

O presente artigou nasceu da necessidade de verificação de metodologias matemáticas que pudessem preencher com o máximo de eficiencia, falhas presentes em séries históricas de banco de dados pluviométricos no Estado do Mato Grosso do Sul.

Essa necessidade foi verificada pelo fato que no decorrer da presente pesquisa de doutorado, e é também encontrada em vários outros trabalhos do campo da Geografia, foram verificadas falhas de preenchimento no banco de dados das estações pluviométricas que serão utilizadas para concluir se está havendo ou não mudanças nos padrões de chuva da região centro-sul do Estado de Mato Grosso do Sul.

A importância do preenchimento para tal pesquisa, deriva do fato de que nesta, procura-se explicação para a expansão da cana-de-açúcar no centro sul do Estado de Mato Grosso do sul, relacionando se tal expansão traz impactos significativos para região, no que concerne as mudanças climáticas globais, sendo estas expressa na figura da pluviosidade, ou seja, na mudança ou não dos padrões de chuva da região. 
Essa preocupação surgiu pelo fato de a cana-de-açúcar ter apresentado expansão significativa no Mato Grosso do Sul, aumentando a área plantada e a instalação de usinas sucroalcooleiras.

A questão da mudança da matriz energética é também alvo da pesquisa, que procura mostrar uma contradição na fala que por um lado defende a plantação da cana-de-açúcar para a produção do etanol, mas que por outro, pode estar impactando alguns sistemas ambientais, visto que a tentativa de se obter um combustível totalmente nacional não é recente, mas que os impactos que podem ser gerados só agora começam a ser estudados, conforme afirma Freitas (2013):

Desde 1903 já se pensava no Brasil a possibilidade de usar o álcool como combustível. O presidente Rodrigues Alves sediou no Rio de Janeiro, em 1903 a Exposição Internacional de Aparelhos a Álcool, com o intuito de divulgar que o álcool produzido nos engenhos, poderia substituir o querosene e a gasolina importados. (FREITAS 2013 p.189).

Assim, verificando-se o banco de dados para tal investigação, observou-se que dos primeiros trinta e seis postos verificados para tal objetivo,nenhum havia a série história, (de 1980 a 2015) completa e sem falhas e por tal motivo as duas metodologias foram utilizadas, com o objetivo tanto do preenchimento quanto da verificação de diferenças matemáticas significativas para esta atividade.

\section{Metodologia}

O principal objetivo do preenchimento das falhas é para que de posse de um banco de dados consistente, seja possível verificar se está havendo ou não mudança nos padrões de chuva da região. Essa hipótese é levantada pelo fato da área em questão concentrar grande parte das usinas sucroalcooleiras do Estado de Mato Grosso do Sul, conforme no mostra o mapa um, que traz em destaque a região estudada e as usinas ali contidas: 

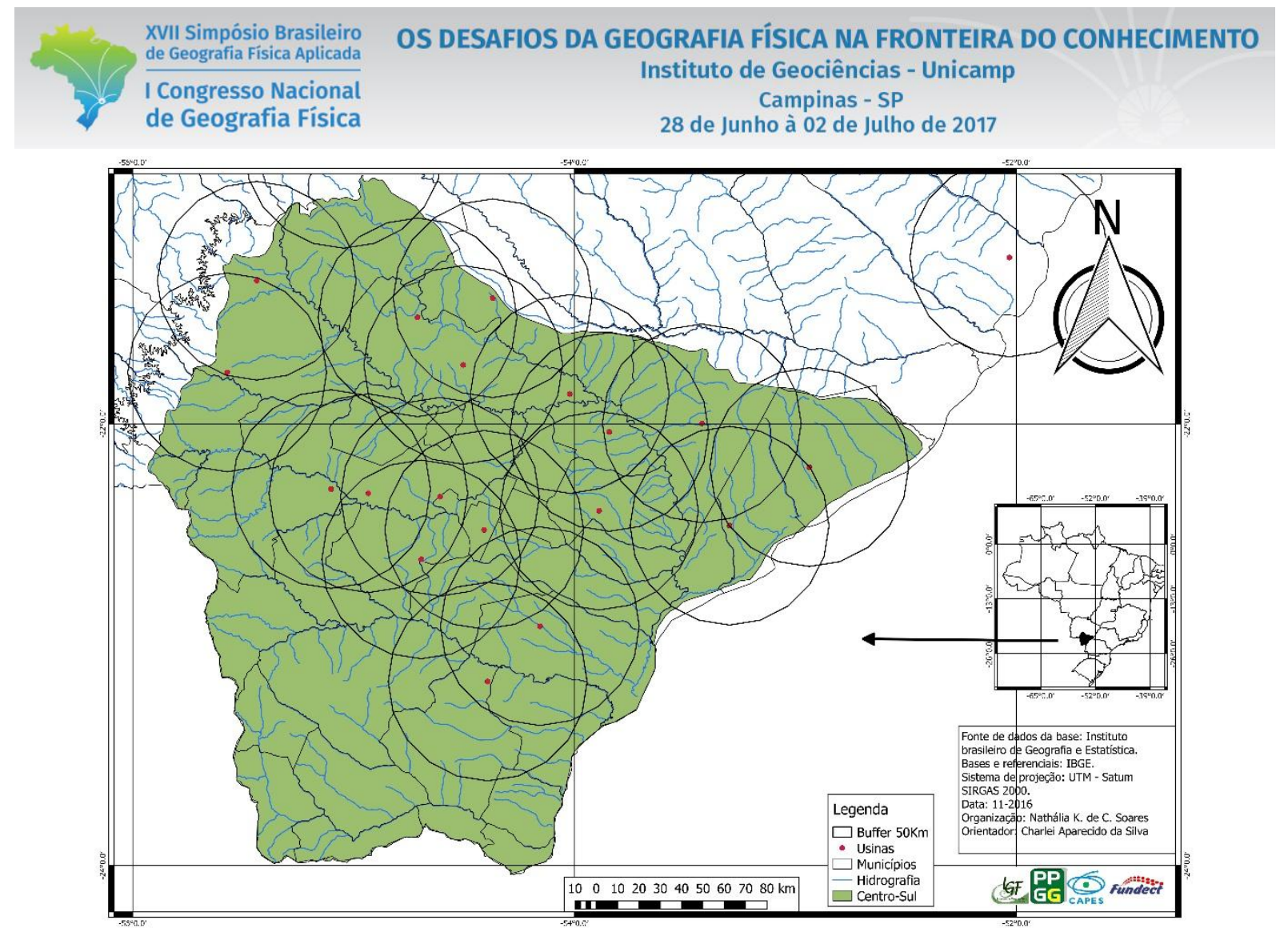

Figura 01: Área de estudo e usinas sucroalcooleiras.

A pesquisa ainda considera como área de influência das usinas, uma extenção de $50 \mathrm{~km}$ ao redor destas, sendo possível observar com o mapa 01 que a região centro sul do Estado do Mato Grosso do sul se encontra quase na sua totalidade sob tal influência. Esta distância de $50 \mathrm{~km}$ em média da área de influência das usinas sucroalcooleiras leva em consideração a logística para o processamento da cana-deaçúcar, e também as propriendades instrinsecas à planta, que para ter suas propriedades conservadas no ato do processamento não podem estar muito distantes do local que isto irá se dar, conforme afirma Castillo (2015):

... de um ponto de vista puramente geométrico, calcula-se que a usina deve estar situada no centro de um círculo ocupado por canaviais, cujo raio seria de 40 a 50 Km em média (CASTILlO, 2013; CONAB, 2013; SAMPAIO, 2015; PINHEIRO, 2015). No entanto, mais importante do que a distância física é a distância medida em custo e, sobretudo neste caso, em tempo. Por isso, a logística de abastecimento local das usinas é um elemento central da organização produtiva. Outras condições geográficas locais e regionais também exercem um papel de destaque na localização e no desempenho das usinas, tais como a topografia, as restrições ambientais, a estrutura fundiária, o nível de organização de movimentos de resistência, o uso da terra etc. (CASTILLO 2015 p. 98). 


$\begin{aligned} & \text { XVII Simpósio Brasileiro } \\ & \text { de Geografia Fisica Aplicada }\end{aligned}$
$\begin{aligned} & \text { I Congresso Nacional } \\ & \text { de Geografia Física }\end{aligned}$

Assim, a fim de cobrir a área escolhida e proporcionar o cruzamento de dados entre a área plantada de cana-de-açúcar e a pluviosidade no período de 1980 a 2015, foram realizados levantamentos e alguns postos eleitos por apresentarem uma boa série histórica de dados e relativa facilidade de acesso aos mesmos. A disposição dos postos localizados na área e que estão contribuindo com a pesquisa podem ser observados no mapa 02 :

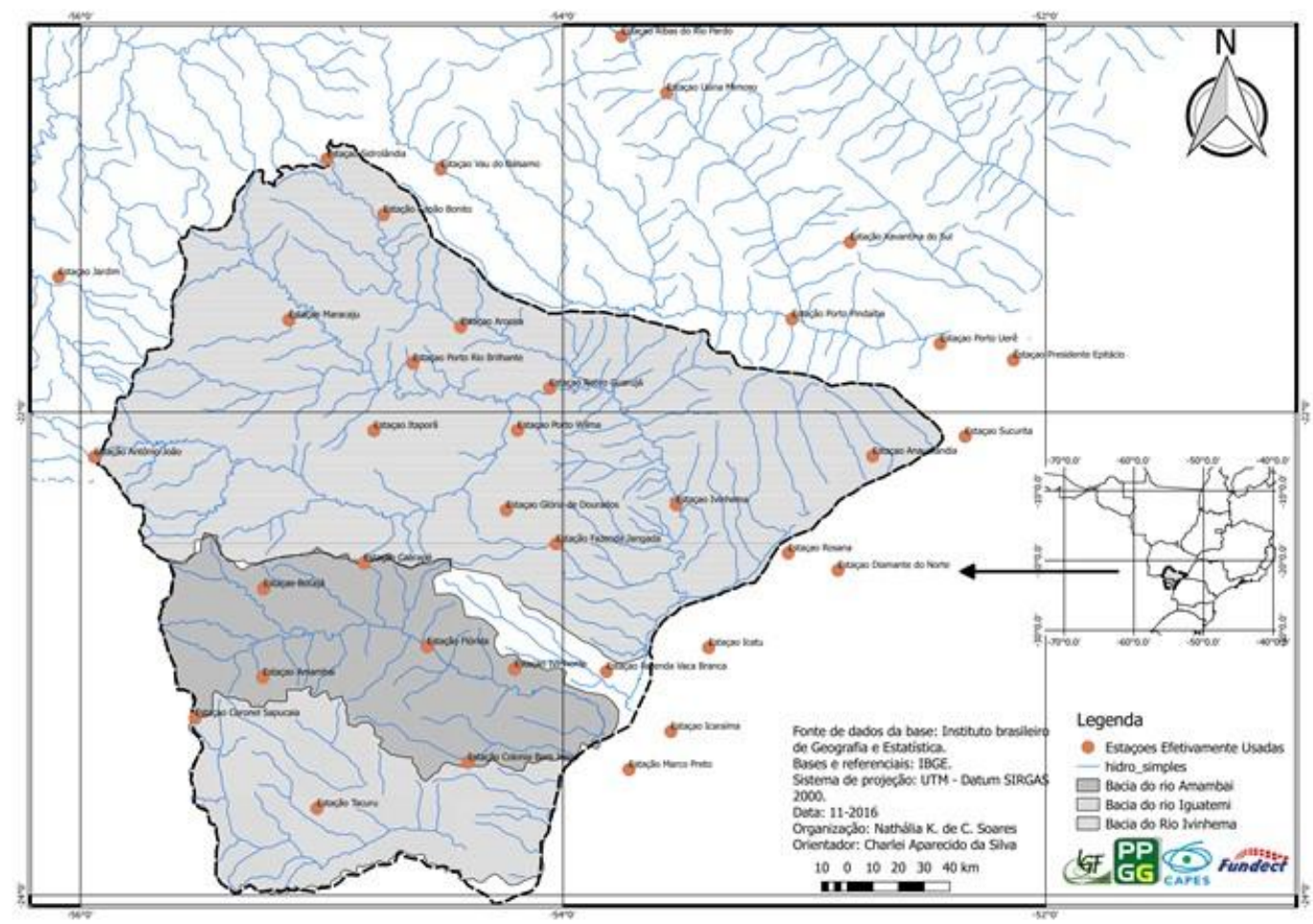

Figura 02: Estações pluviométricas distribuídas na área de estudo.

Assim, de posse das principais informações e do banco de dados de todas as estações em valores diários, foi necessária uma metodologia que contemplasse de maneira correta a correção das falhas contidas pela falta de medição em dias e até meses inteiros de algumas estações. Duas metodologias foram aplicadas na pesquisa, a fim de verificar qual delas melhor se aplicaria: a média aritmética e a ponderação regional com base em regressão linear. No presente artigo, mostrar-se-á essas metodologias aplicadas ao posto “Anaurilândia". 


\section{Média aritmética:}

A média aritmética simples é um modelo matemático bastante utilizado nos mais diversos ramos do conhecimento. Na pesquisa em questão, optamos por utilizá-la para estimar o valor da falha no banco de dados a partir dos três postos mais próximos:

$$
\bar{x}=\frac{x_{1}+x_{2}+\ldots+x_{n}}{n}=\frac{1}{n} \sum_{i=1}^{n} x_{i}
$$

A localização dos postos mais próximos foi feita através do programa Hridroplu, produzido e disponibilizado pela Agência Nacional de Águas (ANA) em parceria com a Universidade Federal de Viçosa. Com o código localizador de cada estação, o hidroplu disponibiliza as estações mais próximas de acordo com o raio previamente estabelecido pelo usuário, conforme observamos na figura 01 a interface do programa:

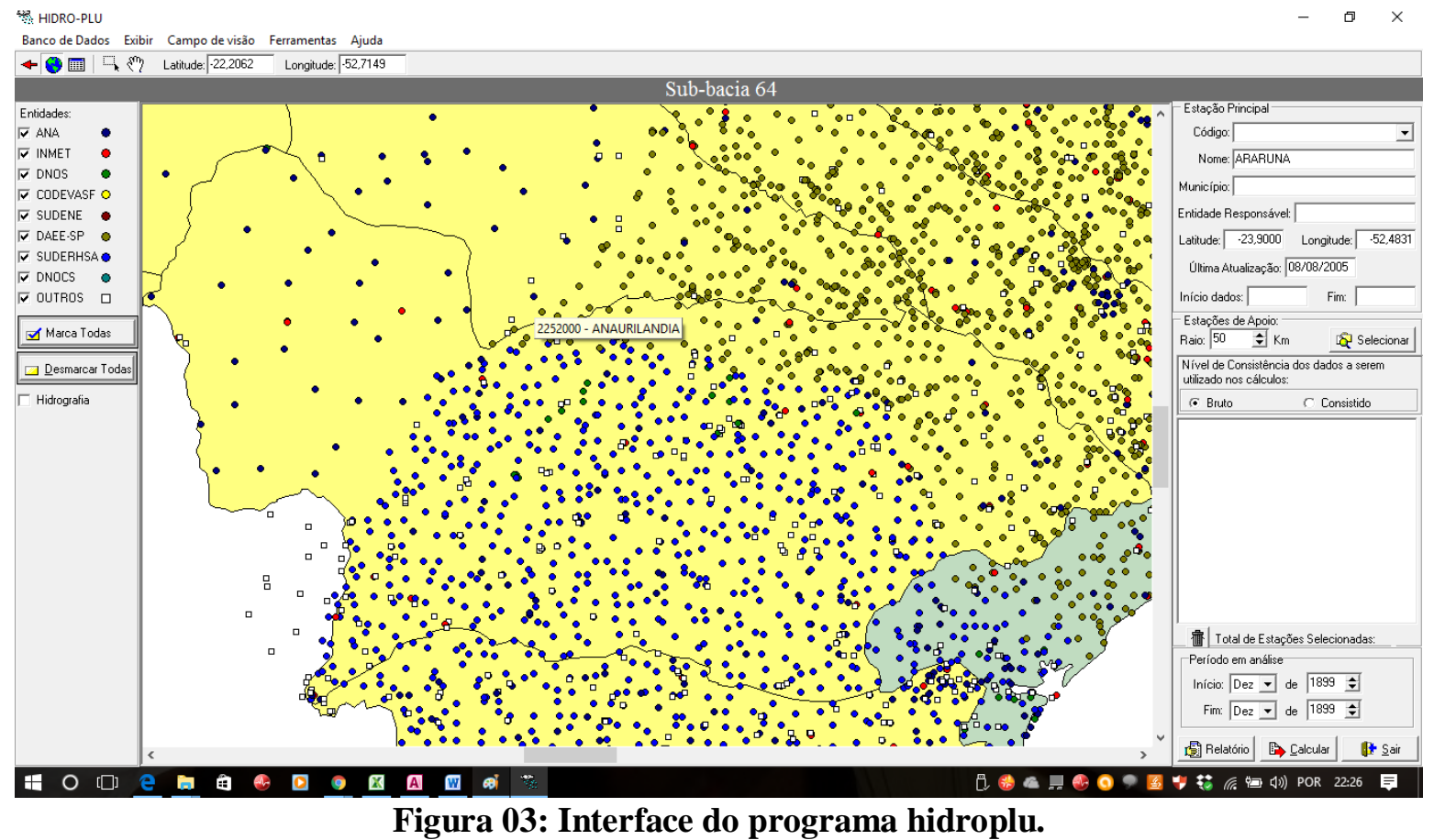

Assim, as falhas foram preenchidas com a média dos três postos mais próximos e que possuíam o dado em questão, conforme pode-se verificar na figura 02, que contem o posto de Anaurilândia com a série histórica de 1980 a 2015 completa, já com as correções em média aritmética, apenas lembrando que as falhas nas séries históricas é algo corriqueiro nas pesquisas desta natureza, e assim, não exclusivo desta: 


\section{OS DESAFIOS DA GEOGRAFIA FÍSICA NA FRONTEIRA DO CONHECIMENTO \\ Instituto de Geociências - Unicamp \\ Campinas - SP \\ 28 de Junho à 02 de Julho de 2017}

de Geografia Física

“A Agência Nacional das Águas disponibiliza as séries pluviométricas pelo sistema de informações hidrológicas Hidro Web, nas quais se observam falhas diárias, mensais e anuais, muitas vezes inviabilizando a utilização dessas séries. A existência de falhas nas séries históricas se deve, basicamente, à ausência do observador, falhas nos mecanismos de registro, perda das anotações ou das transcrições dos registros pelos operadores e encerramento das observações entretanto, como existe a necessidade de se trabalhar com séries contínuas, essas falhas necessitam ser preenchidas (Streck et al., 2009; Bertoni\& Tucci, 2007)". (OLIVEIRAet al 2010 p.1187). 


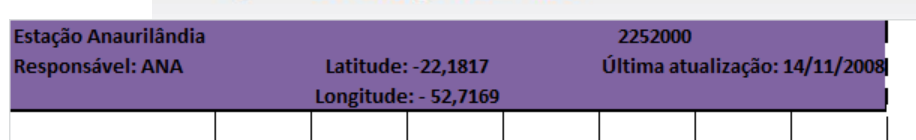

\begin{tabular}{|c|c|c|c|c|c|c|c|c|c|c|c|c|c|c|c|c|c|}
\hline & jan & fev & mar & $a b r$ & mai & jun & |u| & go & set & out & nov & dez & Total anual & Verão & Outono & iverno & Primavera \\
\hline 1980 & 227,7 & \begin{tabular}{|l|}
360,8 \\
\end{tabular} & 85,4 & 80 & 162 & 25,2 & 20,4 & 27 & 204,6 & 90,6 & \begin{tabular}{|l|} 
\\
\end{tabular} & \begin{tabular}{|l|}
188,5 \\
\end{tabular} & 1631,9 & \begin{tabular}{|l|}
673,9 \\
\end{tabular} & \begin{tabular}{|l|}
267,2 \\
\end{tabular} & 252 & 438,8 \\
\hline 1981 & 192,7 & 96,2 & 95,2 & 129,2 & 0 & 135,2 & 7 & 19,5 & 31,2 & 201,3 & 98,5 & 233,9 & 1239,9 & 384,1 & 264,4 & 57,7 & 533,7 \\
\hline 1982 & 38,5 & 145,8 & 213,4 & 81 & 103,1 & 193,5 & 47,2 & 32,7 & 47,8 & & 175,4 & 299,6 & 1378 & 397,7 & 377,6 & 127,7 & 475 \\
\hline 1983 & 289,2 & 69,8 & 303,7 & 160,7 & 201,4 & 173,7 & 6,9 & 0 & 166,2 & 107,8 & 154 & 142,1 & 1775,5 & 662,7 & 535,8 & 173,1 & 403,9 \\
\hline 1984 & 49,9 & 81,5 & 256,5 & 101,6 & 11 & 2 & 7 & 22,8 & 112 & 84 & 130,2 & 290,2 & 1148,7 & 387,9 & 114,6 & 141,8 & 504,4 \\
\hline 1985 & 94,6 & 153,5 & 260,4 & 67 & 55 & 25,2 & 35,1 & 12 & 25 & 82,1 & 61,2 & 47,2 & 918,3 & 508,5 & 147,2 & 72,1 & 190,5 \\
\hline 1986 & 132,4 & 129,3 & 149,8 & 77,8 & 134,2 & 0,3 & 22,2 & 122 & 41,2 & 17 & 44 & 139,5 & 1009,7 & 411,5 & 212,3 & 185,4 & 200,5 \\
\hline 1987 & 221,8 & 122 & 31 & 72,8 & 176 & 65 & 54,6 & 25,4 & 81,9 & 186 & 207,7 & 113,8 & 1358 & 374,8 & 313,8 & 161,9 & 507,5 \\
\hline 1988 & 100,2 & 109,5 & 67,9 & 92,9 & 121 & 12,7 & 0 & 0 & 23,9 & 169,9 & 53,1 & 133,2 & 884,3 & 277,6 & 226,6 & 23,9 & 356,2 \\
\hline 1989 & 428,9 & 111,1 & 150,8 & 76,4 & 57,2 & 64,4 & 52,4 & 125,4 & 109,4 & 107 & 100,9 & 191,8 & 1575,7 & 690,8 & 198 & 287,2 & 399,7 \\
\hline 1990 & 403,9 & 19,8 & 71,5 & 176,2 & 133,2 & 42,9 & 71,7 & 170,6 & 206,5 & 101,7 & 212,7 & 161,9 & 1772,6 & 495,2 & 352,3 & 448,8 & 476,3 \\
\hline 1991 & 128,9 & 72,4 & 98,9 & 64,4 & 38,2 & 97,1 & 11,3 & 0 & 97,8 & 87,2 & 111,7 & 325,6 & 1133,5 & 300,2 & 199,7 & 109,1 & 524,5 \\
\hline 1992 & 74,6 & 142,3 & 261,8 & 183,5 & 252,1 & 29,1 & 40,9 & 40,5 & 179,4 & 77,7 & 113,7 & 110,5 & 1506,1 & 478,7 & 464,7 & 260,8 & 301,9 \\
\hline 1993 & 125,8 & 312,8 & 150,2 & $\begin{array}{l}113,7 \\
\end{array}$ & 94 & $\begin{array}{ll}70,3 \\
\end{array}$ & $\begin{array}{l}70,7 \\
\end{array}$ & 23,3 & 113,9 & $\begin{array}{ll}155,3 \\
\end{array}$ & 92,2 & 91,6 & 1413,8 & 588,8 & 278 & 207,9 & 339,1 \\
\hline 1994 & 209 & 249,1 & 60,9 & 49,7 & 129,1 & 85,1 & 17,8 & 0 & 65,9 & 122,5 & 87,2 & 105 & 1181,3 & 519 & 263,9 & 83,7 & 314,7 \\
\hline 1995 & 228,2 & 142,9 & 200,7 & 96,1 & 7,4 & 16,9 & 18,3 & 10,6 & 303,5 & 220,7 & 81,6 & 231,5 & 1558,4 & 571,8 & 120,4 & 332,4 & 533,8 \\
\hline 1996 & 361,4 & 125,1 & 153,1 & 110,6 & 123 & 4,2 & 5,5 & 39,9 & 103 & 264,3 & 248,9 & 129,8 & 1668,8 & 639,6 & 237,8 & 148,4 & 643 \\
\hline 1997 & 302,7 & 202,4 & 64,4 & 53,7 & 55,7 & 282,2 & 13 & 2,1 & 67,9 & 221,6 & 206,3 & 154,2 & 1626,2 & 569,5 & 391,6 & 83 & 582,1 \\
\hline 1998 & 88,2 & 110 & 212,3 & 180,3 & 106,2 & 26,2 & 17,86 & 88 & 221,6 & 166,3 & 84,2 & 86,3 & 1387,46 & 410,5 & 312,7 & 327,46 & 336,8 \\
\hline 1999 & 118,4 & 144,6 & 49,3 & 207 & 59,2 & 86,3 & 18 & 0 & 10 & 16,43 & 11,6 & 102,3 & 823,13 & 312,3 & 352,5 & 28 & 130,33 \\
\hline 2000 & 43,2 & 253,8 & 53,2 & 40,7 & $\begin{array}{l}4,7 \\
\end{array}$ & \begin{tabular}{l|l|}
120,8 \\
\end{tabular} & 48,6 & $\begin{array}{l}197,3 \\
\end{array}$ & $\begin{array}{ll}84,6 \\
\end{array}$ & 26,8 & 131,1 & $\begin{array}{l}178,8 \\
\end{array}$ & 1183,6 & 350,2 & 166,2 & 330,5 & 336,7 \\
\hline 2001 & 261,5 & 361,7 & 225,4 & 110,5 & 199,5 & 71,8 & 30,3 & 94,2 & 118,7 & 79,8 & 191 & 158,5 & 1902,9 & 848,6 & 381,8 & 243,2 & 429,3 \\
\hline 2002 & 190,5 & 177,1 & 124,2 & 2,9 & 188,2 & 0 & 110,3 & 27,3 & 34,3 & 141 & 45,6 & 184,7 & 1226,1 & 491,8 & 191,1 & 171,9 & 371,3 \\
\hline 2003 & 581,5 & 342,5 & 181,6 & 103,6 & 38,9 & 11,7 & 51 & 91,6 & 47,5 & 168,8 & 84,5 & 201,1 & 1904,3 & 1105,6 & 154,2 & 190,1 & 454,4 \\
\hline 2004 & 0 & 48,2 & 93,3 & 107,9 & 534,4 & 33,1 & 0 & 0 & 169 & 259,13 & 197,13 & 83,6 & 1525,76 & 141,5 & 675,4 & 169 & 539,86 \\
\hline 2005 & 277,3 & 34 & 43,2 & 159,5 & 42,2 & 52,3 & 6,4 & 6,8 & 166,8 & 131,1 & 48,8 & 107,4 & 1075,8 & 354,5 & 254 & 180 & 287,3 \\
\hline 2006 & 144,7 & 290,7 & 198,3 & 115 & 34,4 & 13,5 & 23,5 & 3,6 & 95,6 & 66 & 29,1 & 231,6 & 1246 & 633,7 & 162,9 & 122,7 & 326,7 \\
\hline 2007 & 241,1 & 233,6 & 61,7 & 36,2 & 16,5 & 0 & 148,9 & 0 & 2,1 & 141,3 & $\begin{array}{ll}162,3 \\
\end{array}$ & 184,1 & 1227,8 & 536,4 & 52,7 & 151 & 487,7 \\
\hline 2008 & \begin{tabular}{|c|}
85,6 \\
\end{tabular} & 164 & 93,2 & 51 & 27,8 & 3,2 & 0 & 96,1 & $\begin{array}{ll}87,6 \\
\end{array}$ & 106,4 & $\begin{array}{l}197,6 \\
\end{array}$ & 149,4 & \begin{tabular}{|l|}
1061,9 \\
\end{tabular} & 342,8 & 82 & 183,7 & 453,4 \\
\hline 2009 & 360,7 & 251,4 & 121,8 & 0 & 40,1 & 29,2 & 101,5 & 77,3 & 222,1 & 223,3 & 229,2 & 205,6 & 1862,2 & 733,9 & 69,3 & 400,9 & 658,1 \\
\hline 2010 & 503,3 & 252 & 281,8 & 15 & 156,7 & 0 & 37,3 & 0 & 310,2 & 0 & 129,9 & 126,3 & 1812,5 & 1037,1 & 171,7 & 347,5 & 256,2 \\
\hline 2011 & 58,4 & 275,2 & 119,1 & 159,3 & 25,7 & 64 & 39,4 & 53,4 & 16 & 159 & 162,2 & 30,7 & 1162,4 & 452,7 & 249 & 108,8 & 351,9 \\
\hline 2012 & 71 & 194 & 237,7 & 211,3 & 171,4 & 230,3 & 50,1 & & 101 & 22 & 146 & 200 & 1634,8 & 502,7 & 613 & 151,1 & 368 \\
\hline 2013 & 138 & 290 & 113 & 153 & 71 & 169,3 & 36,9 & 30 & 65 & 119,6 & 80 & 86,3 & 1352,1 & 541 & 393,3 & 131,9 & 285,9 \\
\hline 2014 & 157,6 & 123,9 & 128,1 & 129,3 & 91,7 & 38,1 & 96,3 & 16,3 & 230,5 & 16,5 & 164,9 & 149,9 & 1343,1 & 409,6 & 259,1 & 343,1 & 331,3 \\
\hline 2015 & 165,5 & 191,1 & 1116,8 & \begin{tabular}{|l|}
84,5 \\
\end{tabular} & \begin{tabular}{|l|}
109 \\
\end{tabular} & 25 & 135,3 & \begin{tabular}{|l|l|}
16,7 \\
\end{tabular} & 190,3 & 296,5 & 321,4 & 297,1 & 1949,2 & \begin{tabular}{|l|l}
473,4 \\
\end{tabular} & 218,5 & 342,3 & 915 \\
\hline
\end{tabular}

\begin{tabular}{|l|c|c|l|l|l|}
\hline Correção & Posto recanto porto 10 & 2252031 & & $30 \mathrm{~km}$ \\
\hline & Posto Guanã & 2252036 & & $30 \mathrm{~km}$ \\
\hline & Posto Alcídia & 2252048 & & $30 \mathrm{~km}$ \\
\hline
\end{tabular}

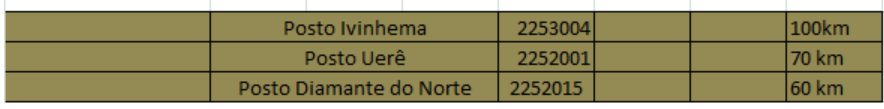

Figura 04: Série histórica do posto de Anaurilândia-MS por média aritmética. 
Assim, é possível verificar que as falhas da série destacadas em rosa, foram preenchidas com base na média aritmética dos postos sinalizados abaixo da tabela (Posto Recanto porto 10, Posto Guanã e posto Alcídia), enquanto as falhas sinalizadas na série em marrom foram preenchidas com o mesmo método, mas com outras estações, já quem nem sempre é possível a correção de toda a série com os mesmos postos, devido a todos conter falhas.

\section{Ponderação regional com base em regressão linear.}

"O método da ponderação regional com base em regressões lineares, segundo Pruskiet al. (2004) e Bertoni\& Tucci (2007), é uma combinação dos métodos anteriores descritos. Este método consiste em estabelecer regressões lineares entre os postos com dados a serem preenchidos, Px , e cada um dos postos vizinhos, P1 , P2 , .., PN. De cada uma das regressões lineares efetuadas obtémse o coeficiente de correlação..." (OLIVEIRA et al 2010 p.1188).

Após a correção das falhas da estação Anaurilândia pelo método da média aritmética pelos três postos mais próximos, optou por testar outra, a fim de pautar corretamente a tese em seu aspecto de metodologia. A ponderação regional com base em regressão linear foi então aplicada tendo já como base outros trabalhos no âmbito da geografia, como por exemplo, Oliveira et al. (2010), Fante e Neto (2013), Carvalho et al. (2006), entre outros.

É importante salientar que uma metodologia julgada como sendo melhor para uma pesquisa, pode não atender em outra, por isso a verificação e posterior comparação dos métodos é de extrema necessidade.

Assim, a mesma tabela usada para o posto em questão no presente trabalho, que possui quatro falhas em sua série histórica, fica da seguinte maneira quando preenchido pelo método da ponderação regional com base em regressão linear. 


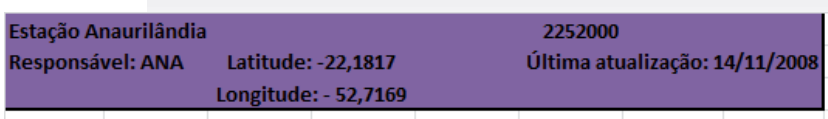

28 de Junho à 02 de Julho de 2017

\begin{tabular}{|c|c|c|c|c|c|c|c|c|c|c|c|c|c|c|c|c|c|}
\hline & jan & fev & mar & abr & mai & jun & jul & ago & set & out & nov & dez & Total anual & Verão & Outono & nverno & Primavera \\
\hline 1980 & \begin{tabular}{|l|}
227,7 \\
\end{tabular} & \begin{tabular}{|r|}
360,8 \\
\end{tabular} & 85,4 & 80 & 162 & 25,2 & 20,4 & 27 & 204,6 & 90,6 & \begin{tabular}{|r|} 
\\
\end{tabular} & \begin{tabular}{|l|l|} 
& 188,5 \\
\end{tabular} & \begin{tabular}{|r|} 
\\
\end{tabular} & 673,9 & \begin{tabular}{|l|l|}
9 & 267,2 \\
\end{tabular} & 252 & 438,8 \\
\hline 1982 & 38,5 & 145,8 & 213,4 & 81 & 103,1 & 193,5 & 47,2 & 32,7 & 47,8 & & 175,4 & 299,6 & 1378 & 397,7 & 377,6 & 127,7 & 475 \\
\hline 1983 & 289,2 & 69,8 & 303,7 & 160,7 & 201,4 & $\begin{array}{ll}173,7 \\
\end{array}$ & 6,9 & 0 & 166,2 & 107,8 & 154 & 142,1 & 1775,5 & 662,7 & 535,8 & 173,1 & 403,9 \\
\hline 1985 & 94,6 & 153,5 & 260,4 & $\begin{array}{l}67 \\
\end{array}$ & 55 & 25,2 & 35,1 & 12 & 25 & 82,1 & 61,2 & 47,2 & 918,3 & 508,5 & 147,2 & 72,1 & 190,5 \\
\hline 1986 & 132,4 & 129,3 & 149,8 & 77,8 & 134,2 & 0,3 & 22,2 & 122 & 41,2 & 17 & 44 & 139,5 & 1009,7 & 411,5 & 212,3 & 185,4 & 200,5 \\
\hline 1987 & 221,8 & 122 & 31 & 72,8 & 176 & 65 & 54,6 & 25,4 & 81,9 & 186 & 207,7 & 113,8 & 1358 & 374,8 & 313,8 & 161,9 & 507,5 \\
\hline 1988 & 100,2 & 109,5 & 67,9 & 92,9 & 121 & 12,7 & 0 & 0 & 23,9 & 169,9 & 53,1 & 133,2 & 884,3 & 277,6 & 226,6 & 23,9 & 356,2 \\
\hline 1991 & 128,9 & 72,4 & 98,9 & 64,4 & 38,2 & 97,1 & 11,3 & 0 & 97,8 & 87,2 & 111,7 & 325,6 & 1133,5 & 300,2 & 199,7 & 109,1 & 524,5 \\
\hline 1992 & 74,6 & 142,3 & 261,8 & 183,5 & 252,1 & 29,1 & 40,9 & 40,5 & $\begin{array}{ll}179,4 \\
\end{array}$ & 77,7 & \begin{tabular}{ll|}
113,7 \\
\end{tabular} & 110,5 & 1506,1 & 478,7 & 464,7 & 260,8 & 301,9 \\
\hline 1993 & 125,8 & 312,8 & 150,2 & 113,7 & 94 & 70,3 & 70,7 & 23,3 & 113,9 & 155,3 & 92,2 & 91,6 & 1413,8 & 588,8 & 278 & 207,9 & 339,1 \\
\hline 1994 & 209 & 249,1 & 60,9 & 49,7 & 129,1 & 85,1 & 17,8 & 0 & 65,9 & 122,5 & 87,2 & 105 & 1181,3 & 519 & 263,9 & 83,7 & 314,7 \\
\hline 1995 & 228,2 & 142,9 & 200,7 & 96,1 & 7,4 & 16,9 & 18,3 & 10,6 & 303,5 & 220,7 & 81,6 & 231,5 & 1558,4 & 571,8 & 120,4 & 332,4 & 533,8 \\
\hline 1996 & 361,4 & $\begin{array}{l}125,1 \\
\end{array}$ & 153,1 & 110,6 & 123 & 4,2 & 5,5 & 39,9 & 103 & 264,3 & 248,9 & 129,8 & 1668,8 & 639,6 & 237,8 & 148,4 & 643 \\
\hline 1997 & 302,7 & 202,4 & 64,4 & 53,7 & 55,7 & 282,2 & 13 & 2,1 & 67,9 & 221,6 & 206,3 & 154,2 & 1626,2 & 569,5 & 391,6 & 83 & 582,1 \\
\hline 2003 & 581,5 & 342,5 & \begin{tabular}{|l|l|}
181,6 \\
\end{tabular} & \begin{tabular}{|l|}
103,6 \\
\end{tabular} & 38,9 & \begin{tabular}{|l|}
11,7 \\
\end{tabular} & 51 & $\begin{array}{l}91,6 \\
\end{array}$ & 47,5 & 168,8 & 84,5 & 201,1 & \begin{tabular}{|l|}
1904,3 \\
\end{tabular} & 1105,6 & 154,2 & 190,1 & 454,4 \\
\hline 2004 & 0 & 48,2 & 93,3 & 107,9 & 534,4 & 33,1 & 0 & 0 & 169 & 211,20 & 175,23 & 83,6 & 1525,76 & 141,5 & 675,4 & 169 & 539,86 \\
\hline 2005 & 277,3 & 34 & 43,2 & $\begin{array}{ll}159,5 \\
\end{array}$ & 42,2 & 52,3 & 6,4 & 6,8 & $\begin{array}{ll}166,8 \\
\end{array}$ & 131,10 & 48,8 & \begin{tabular}{|l|l|}
107,4 \\
\end{tabular} & $\begin{array}{l}1075,8 \\
\end{array}$ & 354,5 & 254 & 180 & 287,3 \\
\hline 2006 & 144,7 & 290,7 & 198,3 & 115 & 34,4 & 13,5 & 23,5 & 3,6 & $\begin{array}{l}95,6 \\
\end{array}$ & 66 & 29,1 & 231,6 & 1246 & 633,7 & 162,9 & 122,7 & 326,7 \\
\hline 2007 & 241,1 & 233,6 & $\begin{array}{l}61,7 \\
\end{array}$ & 36,2 & 16,5 & 0 & 148,9 & 0 & 2,1 & \begin{tabular}{|l|l|}
141,3 \\
\end{tabular} & $\begin{array}{ll}162,3 \\
\end{array}$ & 184,1 & 1227,8 & 536,4 & 52,7 & 151 & 487,7 \\
\hline 2008 & 85,6 & 164 & 93,2 & 51 & 27,8 & 3,2 & 0 & 96,1 & 87,6 & 106,4 & 197,6 & 149,4 & 1061,9 & 342,8 & 82 & 183,7 & 453,4 \\
\hline 2009 & 360,7 & 251,4 & 121,8 & 0 & 40,1 & 29,2 & 101,5 & 77,3 & 222,1 & 223,3 & 229,2 & 205,6 & 1862,2 & 733,9 & 69,3 & 400,9 & 658,1 \\
\hline 2010 & 503,3 & 252 & 281,8 & 15 & 156,7 & 0 & 37,3 & 0 & 310,2 & 0 & 129,9 & $\begin{array}{ll}126,3 \\
\end{array}$ & 1812,5 & 1037,1 & 171,7 & 347,5 & 256,2 \\
\hline 2011 & 58,4 & 275,2 & 119,1 & $\begin{array}{ll}159,3 \\
\end{array}$ & 25,7 & 64 & 39,4 & 53,4 & 16 & 159 & 162,2 & 30,7 & 1162,4 & 452,7 & 249 & 108,8 & 351,9 \\
\hline 2012 & 71 & 194 & 237,7 & 211,3 & 171,4 & 230,3 & 50,1 & & 101 & 22 & 146 & 200 & 1634,8 & 502,7 & 613 & 151,1 & 368 \\
\hline 2013 & 138 & 290 & \begin{tabular}{|l|}
113 \\
\end{tabular} & \begin{tabular}{|l|}
153 \\
\end{tabular} & 71 & $\begin{array}{ll}169,3 \\
\end{array}$ & 36,9 & 30 & 65 & \begin{tabular}{|l|l|}
119,6 \\
\end{tabular} & 80 & 86,3 & 1352,1 & 541 & 393,3 & 131,9 & 285,9 \\
\hline 2014 & 157,6 & 123,9 & 128,1 & 129,3 & 91,7 & 38,1 & $\begin{array}{l}96,3 \\
\end{array}$ & 16,3 & 230,5 & 16,5 & 164,9 & 149,9 & 1343,1 & 409,6 & 259,1 & 343,1 & 331,3 \\
\hline 2015 & 165,5 & 191,1 & 116,8 & \begin{tabular}{l|l}
84,5 \\
\end{tabular} & 109 & 25 & \begin{tabular}{|l|l|}
135,3 \\
\end{tabular} & 16,7 & 190,3 & 296,5 & 321,4 & 297,1 & 1949,2 & 473,4 & 218,5 & 342,3 & 915 \\
\hline & 197,14 & 177,34 & 142,49 & 101,51 & 104,76 & 63,88 & 41,02 & 42,07 & 115,39 & 126,09 & 130,24 & 162,60 & 1401,72 & 516,96 & 270,15 & 196,67 & 417,94 \\
\hline
\end{tabular}

Preenchimento por ponderação regional (Alcídia $30 \mathrm{~km}$ - Fazenda Guaná $20 \mathrm{~km}$-Fazenta Itaporã $40 \mathrm{Km}$ )

Preenchimento por ponderação regional (Fazenda Ponte Branca $40 \mathrm{~km}$ - Diamante do norte $55 \mathrm{~km}$ )

Figura 05: Série histórica do posto de Anaurilândia-MS por Ponderação Regional com base em regressão linear. 
Independente do número de postos utilizados para a correção da falha, a fórmula permanece a mesma, mudando apenas o denominador que corresponde ao total de postos utilizados, sendo que este será 2 se os postos também forem, ou três se forem utilizados três postos, e assim sucessivamente:

De maneira simplificada, temos:

$$
\operatorname{Prec} A=\frac{\text { Med Prec } A}{3}\left(\frac{\operatorname{Prec} B}{\text { Med Prec } B}+\frac{\operatorname{Prec} E}{\text { Med Prec } E}+\frac{\operatorname{Prec} D}{\text { Med Prec D }}\right)
$$

Onde precA é a falha que queremos corrigir e 3 corresponde ao número de postos utilizados na correção.

\section{Conclusão:}

De posse das duas metodologias analisadas temos os seguintes resultados:

Tabela 01: Comparativo entre as metodologias da média aritmética e da ponderação regional com base em regressão linear

\begin{tabular}{|c|c|c|c|c|}
\hline & Julho (1998) & Outubro (1999) & Outubro (2004) & Novembro (2004) \\
\hline $\begin{array}{c}\text { Média } \\
\text { Aritmética }\end{array}$ & 17,86 & 16,43 & 259,13 & 197,13 \\
\hline $\begin{array}{c}\text { Ponderação } \\
\text { regional }\end{array}$ & $\mathbf{2 4 , 6 4}$ & $\mathbf{0 , 0 0}$ & $\mathbf{2 1 1 , 2 0}$ & 175,23 \\
\hline
\end{tabular}

Quando analisados em totais percentuais, a variação para entre os meses com falhas para as duas metodologias é a seguinte:

Em julho de 1998 a média aritmética tem um valor 27,51\% menor que a ponderação regional, uma diferença de 6,78 mm de chuva. Já para outubro de 1999, pelo método da ponderação regional o total de precipitação é zero, enquanto que há $16,43 \mathrm{~mm}$ de chuva pela metodologia da média aritmética. Para o mês de outubro de 2004 a diferença nas análises é de aproximadamente 18,5 \% e em termos totais de 47,93mm a mais para a média aritmética. Por último, o mês de novembro de 2004 demonstrou uma diferença de $11,10 \%$ a mais na precipitação para a média aritmética, perfazendo em termos absolutos $21,9 \mathrm{~mm}$ de chuva de diferença.

Os dados apontam variação de resultados entre as metodologias aplicadas para a área, não havendo uma regra para mais e nem para menos, já que das quatro falhas uma teve resultado de precipitação maior para a ponderação regional e as outras três para a média aritmética. Entretanto, em nenhuma das comparações foi ultrapassada a diferença de $50 \mathrm{~mm}$ mensais, ficando esta diferença entre 6,78 e 47,93 mm mensais. É importante salientar que a área em questão não possui acidentes geográficos significativos, sendo que isto facilita as análises. A maior parte do relevo é formada por planaltos e colinas suaves, que não ultrapassam os $10^{\circ}$ de declividade. 
Embora no exemplo presente neste artigo não ter apresentado grande distorção entre os dados obtidos, ou seja, a média aritmética mostrou-se consistente nesta aplicação, optou na pesquisa que abarca mais de trinta postos, utilizar o método da Ponderação Regional com base em regressão linear, pelo fato desta já possuir maiores consistências nos estudos referentes ao preenchimento de banco de dados em estações pluviais.

A mesma metodologia está sendo aplicada nos demais postos apresentados no mapa 02 do presente trabalho e envolve pesquisa de doutorado "A expansão da cana-de-açúcar no Mato Grosso do Sul: Correlações entre o quadro de mudanças climáticas globais, a matriz energética de biocombustíveis e o regime das chuvas da região centro-sul no período de 1980 a 2015", desenvolvida no laboratório de geografia física da Universidade Federal da Grande Dourados com apoio financeiro da Fundação de Apoio ao Desenvolvimento do Ensino, Ciência e Tecnologia do Estado de Mato Grosso do Sul. (FUNDECT)

\section{REFERÊNCIAS}

ÁGUAS, Agência Nacional de. Hidroplu. $2017 . \quad$ Disponível em: <http://www2.ana.gov.br/Paginas/servicos/informacoeshidrologicas/monitoramentohidro.aspx>. Acesso em: 17 fev. 2017.

CARVALHO, Luís Eduardo Ximenes et al. Regressão linear geograficamente ponderada em ambiente SIG . Transportes, Brasil, v. , n. 2, p.18-26, dez. 2006.

CASTILLO, Ricardo. DINÂMICAS RECENTES DO SETOR SUCROENERGÉTICO NO BRASIL: COMPETITIVIDADE REGIONAL E EXPANSÃO PARA O BIOMA CERRADO. Geographia: As dinâmicas socioespaciais do agronegócio no Brasil e na Argentina, Rio de Janeiro, v. 17, n. 35, p.95-119, nov. 2015. Quadrimestral. Disponível em: 〈http://www.uff.br/geographia/ojs/index.php/geographia/issue/view/39>. Acesso em: 13 mar. 2017.

FANTE, Karime Pechutti; NETO’, João Lima Sant'anna. Aplicação de Técnicas Geo-Estatísticas em Análises Climatológicas: Metodologias para Preenchimento de Falhas. Xv Simpósio Brasileiro de Geografia Física Aplicada, Vitória, v. , n. 1, p.782-790, jul. 2013.

FREITAS, Elisa Pinheiro de. Território, poder e biocombustíveis: as ações do Estado brasileiro no processo de regulação terriotorial para a produção de recursos energéticos alternativos. 2013. Tese de Doutorado. Universidade de São Paulo.

FUNDECT. FUNDAÇÃO DE APOIO AO DESENVOLVIMENTO DO ENSINO, CIÊNCIA E TECNOLOGIA DO ESTADO DE MATO GROSSO DO SUL. Disponível em: <http://fundect.ledes.net/>. Acesso em: 10 fev. 2017.

OLIVEIRA, Luis F. C. de et al. Comparação de metodologias de preenchimento de falhas de séries históricas de precipitação pluvial anual. Revista Brasileira de Engenharia Agrícola e Ambiental, Campina Grande, v. 14, n. 11, p.1186-1192, ago. 2010. 